\title{
A case report of ofloxacin induced fixed drug eruptions and hypersensitivity reaction
}

\author{
Ashraffunnissa Fatima Farheen Kamal ${ }^{1}$, Shrenik H. Vardhamane ${ }^{2}$, Amreen Saba ${ }^{1 *}$
}

${ }^{1}$ Department of Pharmacology, M. R. Medical College, Gulbarga 585105, Karnataka, India

${ }^{2}$ Department of Pharmacology, Khaja Banda Nawaz Institute of Medical Sciences (KBNIMS), Gulbarga 585101, Karnataka, India

Received: 25 April 2017

Revised: 10 June 2017

Accepted: 12 June 2017

\section{*Correspondence to:}

Dr. Amreen Saba,

Email: drattariya90@gmail.com

Copyright: () the author(s), publisher and licensee Medip Academy. This is an openaccess article distributed under the terms of the Creative Commons Attribution NonCommercial License, which permits unrestricted noncommercial use, distribution, and reproduction in any medium, provided the original work is properly cited.

\begin{abstract}
Ofloxacin is the most commonly used first generation fluoroquinolones. Its activity against gram negative organisms lie between Norfloxacin and Ciprofloxacin. It is used for treating infections like UTI, gastroenteritis etc. It is generally well tolerated, gastric upset is the most common adverse effect. However very few cases of Fixed Drug Eruptions have been reported. Here we report a case of a 16year old female patient who developed redness and rashes all over body along with nausea, vomiting, dizziness, palpitations, blurring of vision, headache and loss of consciousness after receiving Tab ofloxacin $200 \mathrm{mg}$ for gastroenteritis. Signs and symptoms subsided within 24 hrs after the drug was stopped and supportive treatment like IV fluids along with dexamethasone was given. Ofloxacin was strongly suspected as the causal drug for the hypersensitivity reaction as the subject had a history of allergic reaction to the same in the past. Early detection of cutaneous lesions and immediate withdrawal of the offending drug can prevent progression of such reactions to their severe variants as well as morbidity and mortality.
\end{abstract}

Keywords: Fixed drug eruptions, Hypersensitivity reaction, Ofloxacin

\section{INTRODUCTION}

Ofloxacin is the most commonly used first generation fluoroquinolones. It is a widely prescribed antimicrobial agent for management of urinary tract infection, acute bacterial diarrheas, enteric fever, STDs and other soft tissue infections. ${ }^{1}$ It's commonly reported side effects include fever, acute renal failure, agranulocytosis and other dermatological reactions. ${ }^{2}$

Cutaneous drug eruptions are one of the most common types of adverse reaction to drug therapy, with an overall incidence rate of $1-5 \% .^{3}$
The term fixed drug eruption describes the development of one or more annular or oval erythematous patches as a result of systemic exposure to a drug; these reactions normally resolve with hyperpigmentation and may recur at the same site with reexposure to the drug. Repeated exposure to the offending drug may cause new lesions to develop in addition to "lighting up" the older hyperpigmented lesions. ${ }^{4}$

\section{CASE REPORT}

A 16yr old female admitted to Basaveshwara teaching and general hospital with presenting complaints of fever, 
nausea, vomiting and 2-3 episodes of loose motions since 2 days, she was prescribed Ofloxacin 200mg twice daily, along with pantoprazole $40 \mathrm{mg}$ thrice daily, loperamide $4 \mathrm{mg}$ twice daily for 3 days, oral rehydration solution sachets were given.

She developed redness and red-purple maculopapular rashes all over body, associated with pruritis and burning sensation along with nausea, vomiting, dizziness, palpitations blurring of vision, headache and loss of consciousness within an hour of taking Ofloxacin, she was brought to hospital in same condition.

Upon history taking, mother of patient revealed a similar episode of reaction 8months back to the drugs given for food poisoning. Few hyperpigmented healed lesions were seen here and there on the skin.

Various investigations: $\mathrm{Hb}-10.8 \mathrm{~g} \%$, Total WBC10,200cells/cumm and differential count PMN-78\%, L$18 \%$, E-04\%, M-0, B-0, ESR-20mm/1 ${ }^{\mathrm{st}} \mathrm{hr}$, Blood urea$34 \mathrm{mg} / \mathrm{dl}$, Serum Creatinine- $1.0 \mathrm{mg} / \mathrm{dl}$, Bilirubin- Total$2.7 \mathrm{mg} / \mathrm{dl}$ and direct- $0.9 \mathrm{mg} / \mathrm{dl}$, AST- $115 \mathrm{U} / \mathrm{L}$, ALT298U/L, Renal function test and urine analysis were normal, Chest radiography and abdominal sonography were unremarkable, Blood sugar was in normal limit. Peripheral smear for malarial parasite, Widal test and HIV test were negative.

The patient was treated symptomatically with Inj. Hydrocortisone $100 \mathrm{mg} \mathrm{IV}^{\text {th }}$ hourly daily, Tab. Cetrizine 10mg OD, Tab. Dimethindene maleate, Inj. Crystalline Penicillin 20lac units $6^{\text {th }}$ hourly, I.V. DNS and I.V D5, Inj. Ranitidine lamp IV BD, and Tab. Paracetamol $500 \mathrm{mg}$ TID and was discharged after 5days of hospitalization when laboratory studies revealed normal reports.

The clinical features with which she presented were similar to those seen in a typical case of fixed drug eruption and hypersensitivity reaction. Signs and symptoms subsided within $24 \mathrm{hrs}$ after Ofloxacin was stopped and supportive treatment.

It's a case of Ofloxacin induced FDE and the patient recovered after stopping Ofloxacin. Further rechallenging was not done in the interest of the patient and due to ethical constraints.

\section{DISCUSSION}

Ofloxacin is a $2^{\text {nd }}$ generation fluoroquinolone and is a racemic mixture of $50 \%$ Levofloxacin and $50 \%$ dextrofloxacin. ${ }^{5}$ Fluoroquinolones block bacterial DNA synthesis by inhibiting bacterial topoisomerase II (DNA Gyrase) and Topoisomerase IV. It has a half-life (t1/2) of 5-7 hours with an oral bioavailability up to $95 \%$. Ofloxacin is administered for both gram negative and gram positive bacteria and is administered in a dose of $400 \mathrm{mg}$ once a day.
Fluoroquinolones are effective in the treatment of urinary tract infection, bacterial diarrhoea and respiratory tract infection and are frequently employed for the same. Ofloxacin is one drug which is usually well tolerated and is devoid of serious adverse reactions. However, in 2004 the US-FDA requested new warning label to be added to all the fluoroquinolones regarding peripheral neuropathy, tendon damage, QTc prolongation, Steven-Johnson syndrome and epidermal necrolysis. ${ }^{6}$

In 1889, Bourns described a series of sharply demarcated hyperpigmented lesions on the lips and tongue of a patient who had recently ingested $20 \mathrm{~g}$ of antipyrine. A few years later, Brocq coined the French term, eruption erythemato-pigmentee fixe, from which we derive the term, fixed drug eruption. ${ }^{7}$

Fixed drug eruptions are cutaneous reaction to ingested drugs and is not uncommon. Typically, FDE begins with a sharply demarcated oval or circinate macule. ${ }^{8}$ Less commonly, FDE appear as plaques, bullae or erosions and may koebnerize. ${ }^{9}$ Although they are usually asymptomatic, there may be associated pruritus, pain, or burning. Each eruption may form solitary or multiple lesions, which typically appear within hours to days after ingestion of the drug. The lesions initially are small and solitary, but may become quite large and numerous. After the initial stage of acute flare, hyperpigmentation of the lesion may follow. Most initial eruptions are localized; recurrent eruptions localize to the same region after rechallenge with the drug (hence, "fixed"). However, the lesions can also be generalized or random. The genitalia, lips, and hands are among the most commonly affected sites, although any site may be affected, including the conjunctivae and oropharynx. ${ }^{10}$

Lesions persist as long as the drug challenge exists and tend to resolve with scaling. Upon re-challenge, lesions typically develop more rapidly than in the first exposure and commonly appear in original and additional sites. The healing process may take days to weeks after the drug is discontinued and may leave a hyperpigmented patch.

Atypical presentations may include non-pigmented, giant $(>20 \mathrm{~cm})$, urticarial, and papular lesions. Thus, FDE may mimic lichen planus, erythema multiforme, StevensJohnson syndrome, paronychia, cheilitis, and psoriasis.

Histologically, FDE demonstrates an interface dermatitis with basal vacuolization and necrosis of keratinocytes, which may lead to sub-epidermal blistering in florid lesions. Lymphocytes and incontinent melanocytes are often found in the epidermis. ${ }^{11}$ Although biopsy may be employed for the diagnosis of FDE, systemic rechallenge is currently the gold standard for diagnosis. Topical application of the drug on a previously lesional site may also prove diagnostic. The treatment of FDE is discontinuation of the drug. If $\mathrm{FDE}$ is severe or 
generalized, corticosteroids may be administered. Successful desensitization has been reported. ${ }^{8}$

Although the pathogenesis of FDE is unknown, antibodies, antibody-dependent cell-mediated cytotoxicity, and serum factors have been implicated. ${ }^{12} \mathrm{~A}$ current hypothesis classifies FDE as a type IVc immunologic reaction because of a latent cytotoxic $\mathrm{T}$ cells in the lesions, which may become reactivated. There is also an association with HLA class I antigens, suggesting that there may be a genetic predisposition to these reactions. The peak incidence of FDE is 21-30 years, although any age may be affected. ${ }^{13}$

Because of the widespread use of fluoroquinolones, it is important to consider these as possible etiologic agents of FDE. The great majority of reports of FDE due to fluoroquinolones have been recent, possibly indicating environmental or evolutionary components. Although most cases of FDE are localized, a few cases (including ours) of generalized FDE have been reported. Therefore, one must include fluoroquinolones in the etiologic differential when making the diagnosis of FDE.

According to Naranjo ADR probability scale, score is 7 and this case is a Probable ADR, and as per WHO-UMC (Uppsala Monitoring Centre) causality assessment system, it fits in Probable/ Likely ADR. ${ }^{14,15}$

\section{CONCLUSION}

Adverse drug reaction has now become one of the leading causes of hospitalization among patients. The major challenge which this case presented was the prompt identification of the offending agent as well as the holistic management of the symptoms exhibited by the patient. The physician should consider better alternative among antibiotics in these cases and also should advise the patient to stop the drug when these reactions persist. Patients are advised to retain the adverse drug reaction information and to provide the same to any physician hitherto treating him/her.

Funding: No funding sources Conflict of interest: None declared

Ethical approval: Not required

\section{REFERENCES}

1. Smythe MA, Rybak MJ. Ofloxacin: a review. Drug Intell Clin Pharm. 1989;23:839-46.
2. Kaur I, Jindal S, Grover IS. Cutaneous Adverse Drug Reaction with Ofloxacin. J Pharmacovigilance. 2014;2:144.

3. Bigby M. Rates of cutaneous reactions to drugs. Arch Dermatol. 2001;137:765-70.

4. Butler DF. Fixed Drug Eruptions. Available at: http://emedicine.medscape.com/article/1336702overview. Accessed 9 January 2016

5. Boopathy D, Prakash M, Mathew B. Method development and validation of simultaneous determination of Ofloxacin and Satranidazole in pharmaceutical dosage form by RP-HPLC. Der Pharmacia Letter. 2010;2(2):22(6).

6. Tanne JH. FDA adds- black box warning label to fluoroquinolone antibiotics. BMJ. 2008;337(7662):135.

7. Nordlund JJ, Boissy RE, Hearing VJ, King RA, Portonne J. The Pigmentary System: Physiology and Pathophysiology. New York: Oxford Univ. Press; 1998.

8. Ozkaya E. Fixed drug eruption: state of the art. J Dtsch Dermatol Ges. Nov 2008;6:181-8 (PubMed).

9. Shiohara T, Mizukawa Y. Fixed Drug Eruption: Easily Overlooked but Needing New Respect. Dermatology. 2002;205:103-4 (PubMed).

10. Wolff K, Johnson RA, Suurmond D, editors. Fitzpatrick's color atlas and synopsis of clinical dermatology. $5^{\text {th }}$ Ed. New York: McGraw Hill; 2005:20:556-558.

11. Barnhill RL, Crowson AN. Textbook of dermatopathology. $2^{\text {nd }}$ Ed. New York: McGraw Hill; 2004:8:179.

12. Scherer K, Bircher AJ. Hypersensitivity reactions to fluoroquinolones. Curr Allergy Asthma. Rep. 2005;5:15-21 (PubMed).

13. Dhar S, Sharma VK. Fixed drug eruption due to ciprofloxacin. British J of Der. 1996;134:156-8 (PubMed).

14. Naranjo CA, Busto U, Sellers EM, Sandor P, Ruiz I, Roberts EA, et al. A method for estimating the probability of adverse drug reactions. Clinical Pharmacology and Therapeutics. 1981;30:239-45.

15. The use of WHO-UMC system for standardized case causality assessment. Available at: http://www.WHO-UMC.org/graphics/4409.pdf

Cite this article as: Kamal AFF, Vardhamane $\mathrm{SH}$, Saba A. A case report of ofloxacin induced fixed drug eruptions and hypersensitivity reaction. Int $\mathbf{J}$ Basic Clin Pharmacol 2017;6:1825-7. 